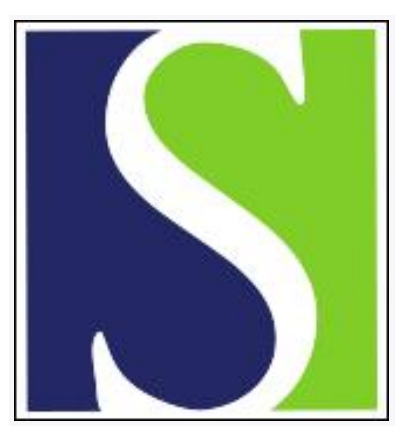

Scand J Work Environ Health 1991;17(1):7-19

https://doi.org/10.5271/sjweh.1731

Issue date: Feb 1991

Mortality from cancer of the colon or rectum among workers exposed to ethyl acrylate and methyl methacrylate.

by Walker AM, Cohen AJ, Loughlin JE, Rothman KJ, DeFonso LR

Affiliation: Epidemiology Resources Inc, Chestnut Hill, Massachusetts 02167.

This article in PubMed: www.ncbi.nlm.nih.gov/pubmed/2047810

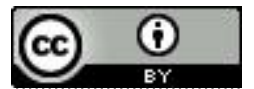




\title{
Mortality from cancer of the colon or rectum among workers exposed to ethyl acrylate and methyl methacrylate
}

\author{
by Alexander M Walker, MD, DrPH, ${ }^{1,2}$ Aaron J Cohen, MPH, ${ }^{1,3}$ Jeanne E Loughlin, MS, ${ }^{1}$ \\ Kenneth J Rothman, DrPH, ${ }^{1}$ Lester R DeFonso ${ }^{4}$
}

\begin{abstract}
WALKER AM, COHEN AJ, LOUGHLIN JE, ROTHMAN KJ, DEFONSO LR. Mortality from cancer of the colon or rectum among workers exposed to ethyl acrylate and methyl methacrylate. Scand $J$ Work Environ Health 1991;17:7-19. Mortality from colon and rectum cancer has been reviewed in three cohorts working in 1933-1982 in two plants manufacturing and polymerizing acrylate monomers. The two cohorts with later dates of hire showed no excess mortality. In the earliest cohort, excess colon cancer seemed restricted to men employed extensively in the early 1940s in jobs entailing the highest exposures to vapor-phase ethyl acrylate (EA) and methyl methacrylate (MMA) monomer and volatile by-products of the EA/MMA polymerization process. The excess mortality appeared only some two decades after the equivalent of three years' employment in jobs with the most intense exposures. A smaller elevation in colon cancer mortality also appeared in a low-exposure group in the early cohort. Rectal cancer mortality was elevated in the same categories that showed excess rates of colon cancer death. Because of the lower rates, the rectal cancer results are more imprecise.
\end{abstract}

Key terms: cohort study.

Ethyl acrylate (EA) and methyl methacrylate (MMA) have been ingredients in the manufacture of acrylic sheet in varying proportions; the use of EA for this purpose was discontinued in the 1950s. In 1984, researchers at Rohm and Haas, who were engaged in a study of respiratory cancer among EA/MMA workers at the company's largest acrylic sheet manufacturing facility, noted that there was an excess of colon cancer among the exposed workers. There were no excesses of respiratory cancer. Subsequent analyses of the experience of workers associated with acrylic sheet manufacture at the large facility (Bristol, Pennsylvania) $)^{5,6}$ and at another, smaller facility (Knoxville, Tennessee) ${ }^{7}$ yielded further results that have met with conflicting interpretations.

Epidemiology Resources Inc, Chestnut Hill, Massachusetts, United States.

2 Department of Epidemiology, Harvard School Public Health, Boston, Massachusetts, United States.

${ }^{3}$ Current address: Health Effects Institute, Cambridge, Massachusetts, United States.

${ }^{4}$ Safety, Health and Environmental Affairs, Rohm and Haas Company, Bristol. Pennsylvania, United States.

5 Maher KV, DeFonso LR. Interim communication on the results of a mortality study of Bristol plant employees hired prior to 1946. Rohm and Haas report, distributed 16 March 1984.

6 Maher KV, DeFonso LR. Mortality study of Bristol plant employees hired 1946-1982. Rohm and Haas report, completed 1987.

7 Maher KV, DeFonso LR. Mortality study of Knoxville plant employees: 1943-1982. Rohm and Haas report, completed 1987.

Reprint requests to: Dr AM Walker, Epidemiology Resources Inc, 826 Boylston Street, Chestnut Hill, MA 02167, USA.
Although the previous work on these data has been subject to regulatory scrutiny, it has not been published. With the aim of making the information more widely available, we have set out to review and analyze all the data on mortality from colon and rectum cancer obtained by Rohm and Haas through the end of 1986, including some material that has not been the subject of previous reports.

\section{History of the plants}

The Bristol plant began operation in 1917. A pilot process for the production of EA monomer was begun in 1931 and full-scale production of EA began in 1933. Polymerization of small quantities of EA with MMA to produce acrylic sheet was begun in 1936. Major expansion of EA/MMA production and acrylic sheet polymerization for the construction of airplane canopies, windows, and other components occurred with the start of the Second World War. The production and finishing of acrylic sheet entailed exposure to EA and MMA monomer and polymers, as well as to a variety of other agents, including some which have subsequently been considered as either probable or possible carcinogens (ratings $2 \mathrm{~A}$ or $2 \mathrm{~B}$ of the International Agency for Research on Cancer): lead, ethylene dichloride, methylene chloride, and acrylonitrile. Some finishing operations also involved exposure to particulate material, and some fabrication operations involved probable exposure to ethylene dichloride, acetone, and MMA monomer as fumes and through the washing of hands, equipment, and clothing. Because 
an explosion in the EA production facility in March of 1943 reduced the availability of EA, the proportion of EA in the polymerization mixture was changed immediately from 12 to $6 \%$. Subsequent changes in production methods resulted in a nearly linear decline to zero in the use of EA in acrylic sheet production ${ }^{5,6}$ in the ensuing decade. EA was, however, used elsewhere in the same buildings in which acrylic sheet was produced, even after its use in acrylic sheet production was discontinued completely.

The Knoxville plant began production of acrylic sheet in 1943 in response to the wartime need for aircraft parts. The production processes were similar to those in effect at the Bristol plant at the time. As at the Bristol plant, the workers were exposed to both EA monomer and MMA monomer, and the jobs that entailed the highest exposures, particularly the "boil out" process, were essentially identical to those at Bristol in their exposure to EA/MMA. By 1946 Rohm and Haas had instituted production and workplace changes that resulted in reduced EA/MMA exposure in both Bristol and Knoxville., 9

Table 1 lists the number of employees hired and terminated, the total number employed, and the percentages of EA, MMA and butyl lactate used in acrylic sheet production in the Bristol and Knoxville plants in $1933-1960$.

\section{Data}

\section{Cohorts}

Three cohorts were assembled. These consisted of male workers who were employed (i) at Bristol before 1946, (ii) later at Bristol, and (iii) at Knoxville. Because of the small numbers of nonwhites in the cohorts, the analyses were restricted to whites.

Early Bristol. The early Bristol cohort comprised 3934 white males employed as hourly workers at any time between 1 January 1933 and 31 December 1945. Of these men, 2906 ( $73.9 \%$ ) were hired between 1941 and 1945. Follow-up began on the first day of employment or on 1 January 1933, whichever came later, and continued until death or 31 December 1986.

Later Bristol. The later Bristol cohort comprised all white males hired during the period 1 January 1946 to 31 December 1982. A total of 6548 men were in this cohort: 3916 hourly employees and 2632 salaried employees. The cohort members entered follow-up on the first day of employment. They were followed until death or 31 December 1986.

\footnotetext{
8 Plexiglas sheet manufacture at Bristol (1937-1945) and Knoxville (1943 - 1945). Unpublished report by DJ Koestler, dated 3 October 1988.

9 Epidemiology of methyl methacrylate and ethylacrylate. A memorandum from $\mathrm{H}$ Baum to I Rosenthal, dated $15 \mathrm{July}$ 1980.
}

Knoxville. The Knoxville cohort comprised the 3381 white males employed at the facility from 1 January 1943 to 31 December 1982. Follow-up was begun on the first day of employment. The cohort members were traced until death or 31 December 1986.

\section{Vital status and cause of death}

Vital status was ascertained from company records, the National Death Index (NDI), and Social Security Administration records. If an employee was actively receiving company or social security benefits, he was determined to be alive. Employees were counted as having died if there was a note of death in the company records, in social security files, or in the NDI, if the last was confirmed by a death certificate identification. Vital status was considered unknown if an employee was not participating in the social security system and was not listed as deceased in the NDI for 1979-1986. The percentages of cohort members known to be alive, known dead, and with unknown vital status were $39.1,50.6$, and 10.3 , respectively, for the early Bristol cohort; 76.5, 15.0, and 8.6, respectively, for the later Bristol cohort; and 58.3, 33.5, and 8.2, respectively, for the Knoxville cohort. A death certificate was located from insurance records or state vital statistics departments for each known decedent. Whenever there was any mention of colon or rectal cancer on any part of the death certificate, the final cause of death was coded by two nosologists according to the revision of the International Classification of Diseases in effect at the time of death. Discordant classifications were resolved by consensus and reference to the relevant coding instructions. In addition all deaths occurring from 1982 through 1986 were coded by two nosologists. Deaths occurring before 1982 for which there was no mention of colon or rectal cancer in the death certificate were coded by a single nosologist.

\section{Exposure}

The EA/MMA exposures of members of the three cohorts were estimated on the basis of workers' job histories and job-specific exposure rating scales. The job histories were abstracted from work records that listed the jobs held and the start and stop dates of each job. Since the only available monitoring data for EA/MMA were from the Bristol plant, beginning in 1972, attempts were made to reconstruct the earlier levels of exposure to EA/MMA from production records and interviews with plant personnel. The resulting scales were semiquantitative, relied on the recollection of long-term employees, pertained to vapor exposure only, did not distinguish between EA and MMA, were not verifiable, and did not take into account the presence of other possibly carcinogenic substances in the workplace. The separate ordinal scales described later in this report for each cohort are not mutually comparable. 
Early Bristol. Each job was assigned a score from zero to five. ${ }^{5}$ A score of five corresponded to work in the "boil-out" phase of acrylic sheet production, where exposure to EA/MMA vapor was judged to have been the most intense. The other exposure levels were constructed relative to level five. Level two was designed to represent "minimal" exposure, and level one included jobs in which exposure may have been absent. Level zero corresponded to jobs believed to have entailed no exposure at all.

Later Bristol. The industrial hygienist of the plant constructed a four-level ordinal exposure scale for MMA vapor based on the 1972 and later monitoring data and on the extrapolation of those data to work areas no longer in operation but which he considered similar to those current work environments for which data were available. ${ }^{6}$ The intent was that a score of three would correspond to an MMA exposure of $25 \mathrm{ppm}$ or greater, two to $5-24 \mathrm{ppm}$, one to less than $5 \mathrm{ppm}$, and zero to "no routine exposure."

Knoxville. A four-level EA/MMA vapor exposure scale was constructed based on a reconstruction of past production practices. ${ }^{7}$ Each job was assigned a rank on this scale for each year that the job title existed. A score of three denoted "major exposure" (ie, "hand operations performed without local exhaust ventilation"). The "boil out" operation is an example of "major exposure." A score of zero denoted "no exposure."

\section{Analyses}

\section{Cohort eligibility}

For each cohort the minimum duration of employment required for entry into the study was chosen as the shortest duration of completed employment for which there was at least $85 \%$ successful follow-up. This rule was chosen without knowledge of the relation of person-time or deaths to the criterion. For the early Bristol cohort, the cutoff defined in this manner was 10 months, and it resulted in the exclusion of 1410 men, leaving 2524 with at least 10 months' employment. For the later Bristol and the Knoxville cohorts, the cutoffs were zero months in each case, and no men were excluded so that the analyzed cohorts contained 6548 and 3381 men, respectively.

\section{Exposure quantification}

The described exposure scales were treated as exposure intensity scores. For each, the lowest (not- exposed) category was assigned a value of zero, and the nextordered categories were assigned scores of one, two, three, and (for the early Bristol cohort) four and five. We derived a total dose for each job held by each worker by multiplying the exposure intensity by the interval in days from start to end of employment in

Table 1. Employees and production capacity at Bristol and Knoxville. (MMA = methyl methacrylate, EA = ethyl ethacrylate, $\mathrm{BL}=$ butyl lactate)

\begin{tabular}{|c|c|c|c|c|c|c|c|c|c|}
\hline \multirow{2}{*}{ Year } & \multicolumn{3}{|c|}{ Bristol } & \multicolumn{3}{|c|}{ Knoxville } & \multicolumn{3}{|c|}{$\begin{array}{l}\text { Percentage of chemicals used } \\
\text { in acrylic sheet manufacture }\end{array}$} \\
\hline & $\begin{array}{l}\text { New } \\
\text { hires }\end{array}$ & $\begin{array}{l}\text { Termi- } \\
\text { nations }\end{array}$ & $\begin{array}{c}\text { Total } \\
\text { employees }\end{array}$ & $\begin{array}{l}\text { New } \\
\text { hires }\end{array}$ & $\begin{array}{l}\text { Termi- } \\
\text { nations }\end{array}$ & $\begin{array}{l}\text { Total } \\
\text { employees }\end{array}$ & MMA & EA & $B L$ \\
\hline 1933 & 41 & - & 156 & $\cdots$ & . & . & . & $\ldots$ & . \\
\hline 1934 & 20 & 1 & 176 & $\cdots$ & $\ldots$ & . & $\cdots$ & $\ldots$ & $\ldots$ \\
\hline 1935 & 21 & 1 & 196 & $\ldots$ & $\ldots$ & $\ldots$ & $\cdots$ & $\ldots$ & $\ldots$ \\
\hline 1936 & 61 & 8 & 256 & $\cdots$ & . & $\cdots$ & . & $\cdots$ & $\cdots$ \\
\hline 1937 & 35 & 6 & 283 & $\cdots$ & . & $\cdots$ & $\cdots$ & . & $\cdots$ \\
\hline 1938 & 59 & 8 & 336 & $\cdots$ & $\cdots$ & $\cdots$ & . & $\cdots$ & $\cdots$ \\
\hline 1939 & 295 & 20 & 623 & $\cdots$ & $\cdots$ & $\ldots$ & 88 & 12 & 0 \\
\hline 1940 & 381 & 38 & 984 & 1 & - & 1 & 88 & 12 & 0 \\
\hline 1941 & 693 & 109 & 1639 & - & - & 1 & 88 & 12 & 0 \\
\hline 1942 & 857 & 414 & 2387 & 5 & - & 6 & 88 & 12 & 0 \\
\hline 1943 & 802 & 611 & 2775 & 1200 & 399 & 1206 & 91 & 7 & 2 \\
\hline 1944 & 427 & 646 & 2591 & 274 & 467 & 1081 & 92 & 6 & 2 \\
\hline 1945 & 127 & 459 & 2072 & 129 & 372 & 743 & 92 & 6 & 2 \\
\hline 1946 & 407 & 374 & 2020 & 36 & 32 & 407 & 92 & 6 & 2 \\
\hline 1947 & 19 & 347 & 1665 & 63 & 35 & 438 & 92 & 6 & 2 \\
\hline 1948 & 104 & 149 & 1422 & 113 & 107 & 516 & 92 & 6 & 2 \\
\hline 1949 & 247 & 115 & 1520 & 56 & 54 & 465 & 93 & 5 & 2 \\
\hline 1950 & 565 & 217 & 1970 & 76 & 30 & 487 & 94 & 4 & 2 \\
\hline 1951 & 509 & 390 & 2262 & 136 & 53 & 593 & 95 & 3 & 2 \\
\hline 1952 & 220 & 330 & 2092 & 38 & 53 & 578 & 96 & 3 & 1 \\
\hline 1953 & 143 & 213 & 1905 & 43 & 35 & 568 & 97 & 2 & 1 \\
\hline 1954 & 161 & 91 & 1853 & 18 & 27 & 551 & 98 & 1 & 1 \\
\hline 1955 & 258 & 107 & 2020 & 63 & 20 & 587 & 99 & 1 & 0 \\
\hline 1956 & 111 & 119 & 2024 & 58 & 32 & 625 & 100 & 0 & 0 \\
\hline 1957 & 77 & 111 & 1982 & 55 & 28 & 648 & 100 & 0 & 0 \\
\hline 1958 & 131 & 94 & 2002 & 15 & 13 & 635 & 100 & 0 & 0 \\
\hline 1959 & 425 & 162 & 2333 & 71 & 20 & 693 & 100 & 0 & 0 \\
\hline 1960 & 251 & 220 & 2422 & 47 & 39 & 720 & 100 & 0 & 0 \\
\hline
\end{tabular}


the job, divided by 365.25 . One unit of accumulated dose could therefore represent, for example, exposure for one year in a job with a dose rating of one, or six months in a job with a rating of two, or three months in a job with a rating of four.

\section{Classification of person-time and deaths}

The possibility of a relation between colon cancer and work in areas rated as having a nonzero level of exposure to EA/MMA was explored in two steps that classified worker experience according to exposure to acrylates and elapsed time and in several subsidiary analyses that were directed at derivative hypotheses. In the first analysis, we examined the effect of elapsed time on cancer mortality, taking as the starting point for time measurements the dates upon which workers crossed various thresholds of predefined cumulative levels of acrylate exposure. In the second, we examined the relation between mortality and the cumulative level of acrylate exposure that had been attained 20 years earlier. In the subsidiary analyses, we examined effects of maximum exposure intensity (as opposed to cumulative exposure) and date of hire.

Time since achievement of threshold levels. The dates of achieving threshold levels of exposure were determined. The thresholds examined were $>0$ units, 5 units, 10 units, and 15 units. The dates at which each worker crossed any of the thresholds were calculated on the assumption that exposure was constant through the interval during which a job was held. For each threshold separately, mortality rates were examined according to the number of completed years elapsed since the threshold had been achieved. The categories used were $0-4$ years, $5-19$ years, and $\geq 20$ years following achievement of the threshold level. For each threshold-specific analysis, the person-time accumulated in each cohort was therefore categorized as: (i) not (yet) exposed to EA/MMA (this category includes time periods of observation both for persons who were never exposed to EA/MMA and for persons who would subsequently be exposed, but had not yet been so); (ii) exposed, but to less than the threshold dose in question; (iii) exposed to the dose in question $(<5$ years elapsed since achievement of the threshold dose, $\geq 5$ years but $<20$ years since achievement of the threshold dose, $\geq 20$ years since achievement of the threshold dose).

Because there were four threshold levels explored, the person-time in each cohort was recategorized and reanalyzed four times, once for each exposure level examined. Although the time intervals following the achievement of specified doses were mutually exclusive, the doses themselves overlapped. That is, when a worker achieved 10 units of exposure, he had necessarily achieved 5 units and $>0$ units at earlier dates.

The analysis for disease patterns as a function of time since achieving $>0$ units of exposure corresponds to the frequently used analysis of "latency" (more properly, "induction time"), defined as the time interval separating observation from first exposure. Analyses for thresholds of 5, 10, and 15 units present the additional consideration of a minimal necessary dose to achieve effect.

Mutually exclusive dose categories. We accomplished an analysis of mutually exclusive dose categories by classifying the entire period of observation of each worker according to the dose that had been achieved 20 years earlier. This analysis was restricted to persontime accumulated 20 years or more following first hire. All observation time was classed according to the number of whole units of exposure achieved 20 years before. The categories of exposure were 0 units, $1-4$ units, $5-9$ units, $10-14$ units, and $\geq 15$ units.

Maximal exposure. The workers were separated according to their highest job-exposure rating, without regard of the job held or the total accumulated exposure. Person-time at risk and deaths following the maximal exposure were accumulated within categories of age and calendar year.

Date of hire. Because of the large number of hires during the Second World War (see table 1) and because of changes in process and ventilation in the 1940s, there was a strong association between dates of hire and both the cumulative exposure to acrylates and the peak exposure to acrylates in the Bristol facility. Worker experience was separated according to year of hire (before 1942, 1942-1944, after 1944). The examination of those hired before 1942 was restricted to workers whose employment continued after 1942, to provide an estimate of effects associated with dates of hire that might be separable from the time-bound effects of the work environment.

Age and year of observation. Within each of the categories of person-time that have already been defined, we established subclasses defined by age in five-year intervals and by calendar time in five-year blocks. Person-time was simultaneously categorized according to age in five-year intervals from age 15 to age $\geq 85$ years and according to calendar years, grouped as 1932-1944, and then by five-year intervals to 1986 .

Within each category defined collectively by exposure, time interval since exposure, age, and calendar period, we summed the included periods of observation of all men in the cohort. One man contributed person-time to all the different categories for which his experience qualified. Deaths from colon or rectal cancers were sorted and assigned to categories that were identical to the categories used to classify person-time. Each death was assigned to the category 
in which the deceased person was accumulating persontime at the moment of his death.

\section{Measures of the effect of exposure}

Mortality. We determined the mortality rates by dividing the numbers of deaths in each subcategory of exposure and time by the amount of person-time accumulated in the same subcategory.

Standardization. Death rates in each category of observation were age-standardized according to the distribution of person-years over age categories between 30 and 84 years, summed over the full period of followup for each cohort. Because of a strong association between ages and calendar years of observation of the cohort and because the experience of different exposure categories embraced different calendar-year periods, standardization by both age and calendar year was impossible. In general, mortality at longer intervals since achievement of any given cumulative exposure reflected person-time in later calendar years. Within the range of dates covered by the reported studies, in the counties where most of the workers resided, the later periods of observation were characterized in the general population by higher death rates from cancers of the colon and lower rates of mortality from cancer of the rectum than were earlier periods. Because of the secular trends in general-population mortality rates, if the experience of the cohorts under study exactly mirrored the mortality patterns of the local populations, then there would be progressively higher age-standardized death rates for colon cancer and lower rates for rectal cancer with increasing time since achievement of any particular cumulative dose.

Expected deaths. Expected counts of deaths were calculated for all exposure/time categories included in the tabular presentations. They were obtained by multiplying the person-years of observation in every ageand calendar-year-specific cell of person-time by the local mortality rates, as provided by the University of Pittsburgh. The data supplied by the University of Pittsburgh comprised the mortality rates and the contributing numbers of deaths observed and estimates of the total person-time under observation in categories of age and calendar time; the category boundaries yielded five-year groupings of age from 15 to 84 years plus $\geq 85$ years, and five-year calendar periods from 1950 through 1979 plus the seven-year period 19801986. County-level mortality rates were unavailable for the period prior to 1950; therefore, we applied 1950-1954 rates to person-time contributed before 1950. The Knoxville rates used were those supplied for Knox County, Tennessee. Bristol workers were drawn from both Burlington County, New Jersey, and Bucks County, Pennsylvania. We derived local Bristol rates by summing the numbers of deaths and the numbers of persons at risk in the two counties in each category of age and calendar period and dividing the first sum by the second.

Model-based measures. Model-based measures invoked an assumption of a single mortality rate ratio or rate difference that characterized the way in which a cohort's hazard of death differed from that of the local population in all age- and calendar-year periods. An overall estimate that is believed to characterize all the subgroups in an analysis is called a "common" estimate. Common estimates in this case were obtained by maximum likelihood methods, using GLIM (generalized linear interactive modeling) (1), and asymptotic $95 \%$ confidence intervals $(95 \% \mathrm{CI})$ were derived on the basis of the estimated variance of the measures. In the analyses that follow, ratio measures appear to have offered better fitting, as well as more stable and more interpretable summaries of the data. Nevertheless, none of the broad conclusions of the present analysis would be different according to the measure of effect employed.

When common rate ratio measures are estimated by maximum likelihood techniques against a general population reference, the resulting estimates are identical to those obtained by standardization to the distribution of the exposed person-time (2). There is no corresponding result for additive measures, which are further restricted by a variety of boundary conditions that do not affect ratio estimates. In the analyses of maximal exposure intensity and of date of hire, we present observed-to-expected ratios as the sole measure of effect. These estimates were developed with the aim of identifying a common ratio effect and should be interpreted as maximum likelihood estimates of the common mortality ratio. Note, however, that these common mortality ratio estimates are algebraically identical to the conventional standardized mortality ratio (SMR). Throughout the analysis, when there were no deaths in a tabulated exposure/time category, for which an asymptotic variance estimate was therefore unavailable, we have taken advantage of the algebraic identity between the estimate and the SMR by calculating exact $95 \%$ confidence bounds for the count of deaths and dividing this by the expected count to obtain $95 \%$ confidence bounds for the mortality ratio.

\section{Results}

\section{Early Bristol colon cancer}

Threshold analysis. Tables $2-6$ present the relation between colon cancer mortality and the time since achievement of a variety of postulated threshold levels of exposure to EA/MMA. In each table, the first row presents data on the person-time that preceded any ex- 
Table 2. Accumulated dose of $>0$ units; mortality from cancer of the colon in the early Bristol cohort among those employed $>10$ months. ( $95 \% \mathrm{Cl}=95 \%$ confidence interval)

\begin{tabular}{|c|c|c|c|c|c|c|c|c|}
\hline & Deaths & $\begin{array}{l}\text { Person- } \\
\text { years }\end{array}$ & $\begin{array}{l}\text { Expected } \\
\text { deaths }\end{array}$ & Rate $^{a}$ & $\begin{array}{l}\text { Fitted rate } \\
\text { difference }^{b}\end{array}$ & $95 \% \mathrm{Cl}$ & $\begin{array}{l}\text { Fitted rate } \\
\text { ratioc }^{c}\end{array}$ & $95 \% \mathrm{Cl}$ \\
\hline Not exposed & 11 & 23487 & 11.48 & 40 & -27 & $-35--18$ & 0.96 & $0.53-1.73$ \\
\hline $\begin{array}{l}\text { Exposed but dose } \\
\text { not achieved }\end{array}$ & - & - & 0.00 & 0 & $\cdot$ & . & $\cdot$ & . \\
\hline \multicolumn{9}{|l|}{$\begin{array}{l}\text { Years since achieve- } \\
\text { ment of dose }\end{array}$} \\
\hline $\begin{array}{l}<5 \\
5-19 \\
\geq 20\end{array}$ & $\begin{array}{r}2 \\
5 \\
31\end{array}$ & $\begin{array}{r}8921 \\
24565 \\
30249\end{array}$ & $\begin{array}{r}0.46 \\
3.54 \\
21.39\end{array}$ & $\begin{array}{l}42 \\
41 \\
69\end{array}$ & $\begin{array}{r}+14 \\
-4 \\
+28\end{array}$ & $\begin{array}{r}-13-+40 \\
-8-\quad 0 \\
-2-+57\end{array}$ & $\begin{array}{l}4.39 \\
1.41 \\
1.45\end{array}$ & $\begin{array}{l}1.10-17.6 \\
0.59-3.39 \\
1.02-2.06\end{array}$ \\
\hline
\end{tabular}

a Deaths per 100000 person-years, standardized to the age distribution of person-time (ages $30-84$ years) observed in the entire cohort.

b Fitted difference between cohort mortality rate and the combined Bucks County, Pennsylvania, and Burlington County, New Jersey, white male mortality rate for the same age and calendar period.

c Fitted ratio of cohort mortality rate and the combined Bucks County and Burlington County white male mortality rate for the same age and calendar period.

Table 3. Accumulated dose of 5 units; mortality from cancer of the colon in the early Bristol cohort among those employed $>10$ months. $(95 \% \mathrm{Cl}=95 \%$ confidence interval)

\begin{tabular}{|c|c|c|c|c|c|c|c|c|}
\hline & Deaths & $\begin{array}{l}\text { Person- } \\
\text { years }\end{array}$ & $\begin{array}{l}\text { Expected } \\
\text { deaths }\end{array}$ & Rate $^{a}$ & $\begin{array}{l}\text { Fitted rate } \\
\text { difference }^{b}\end{array}$ & $95 \% \mathrm{Cl}$ & $\begin{array}{l}\text { Fitted rate } \\
\text { ratioc }\end{array}$ & $95 \% \mathrm{Cl}$ \\
\hline Not exposed & 11 & 23487 & 11.48 & 40 & -27 & $-35--18$ & 0.96 & $0.53-1.73$ \\
\hline $\begin{array}{l}\text { Exposed but dose } \\
\text { not achieved }\end{array}$ & 17 & 31516 & 10.98 & 68 & +17 & $-2-+35$ & 1.55 & $0.96-2.49$ \\
\hline \multicolumn{9}{|l|}{$\begin{array}{l}\text { Years since achieve- } \\
\text { ment of dose }\end{array}$} \\
\hline $\begin{array}{l}<5 \\
5-19 \\
\geq 20\end{array}$ & $\begin{array}{r}- \\
3 \\
18\end{array}$ & $\begin{array}{r}4600 \\
12.919 \\
14700\end{array}$ & $\begin{array}{r}0.26 \\
2.14 \\
12.00\end{array}$ & $\begin{array}{r}0 \\
35 \\
65\end{array}$ & $\begin{array}{r}-22 \\
+1 \\
+24\end{array}$ & $\begin{array}{l}-38--7 \\
-12-+13 \\
-19-+66\end{array}$ & $\begin{array}{l}0.00 \\
1.40 \\
1.50\end{array}$ & $\begin{array}{r}0-14.2 \\
0.45-4.34 \\
0.95-2.38\end{array}$ \\
\hline
\end{tabular}

a Deaths per 100000 person-years, standardized to the age distribution of person-time (ages 30-84 years) observed in the entire cohort.

b Fitted difference between cohort mortality rate and the combined Bucks County, Pennsylvania, and Burlington County, New Jersey, white male mortality rate for the same age and calendar period.

c Fitted ratio of cohort mortality rate and the combined Bucks County and Burlington County white male mortality rate for the same age and calendar period.

Table 4. Accumulated dose of 10 units; mortality from cancer of the colon in the early Bristol cohort among those employed $>10$ months. ( $95 \% \mathrm{Cl}=95 \%$ confidence interval)

\begin{tabular}{lcccccccc}
\hline & Deaths & $\begin{array}{c}\text { Person- } \\
\text { years }\end{array}$ & $\begin{array}{c}\text { Expected } \\
\text { deaths }\end{array}$ & Rate & $\begin{array}{c}\text { Fitted rate } \\
\text { difference }\end{array}$ & $95 \% \mathrm{Cl}$ & $\begin{array}{c}\text { Fitted rate } \\
\text { ratio }\end{array}$ & $95 \% \mathrm{Cl}$ \\
\cline { 2 - 8 } & 11 & 23487 & 11.48 & 40 & -27 & $-35--18$ & 0.96 & $0.53-1.73$ \\
$\begin{array}{l}\text { Not exposed } \\
\begin{array}{l}\text { Exposed but dose } \\
\text { not achieved }\end{array}\end{array}$ & 25 & 45346 & 17.22 & 68 & +13 & $-1-+28$ & 1.45 & $0.98-2.15$ \\
$\begin{array}{l}\text { Years since achieve- } \\
\text { ment of dose }\end{array}$ & & & & & & & & \\
$\quad<5$ & - & 2660 & 0.14 & 0 & -37 & $-62-+12$ & 0.00 & $0-26.4$ \\
$5-19$ & 1 & 7459 & 1.20 & 8 & +2 & $-19-+24$ & 0.84 & $0.12-5.93$ \\
$\geq 20$ & 12 & 8271 & 6.83 & 67 & +25 & $-33-+83$ & 1.76 & $1.00-3.10$ \\
\hline
\end{tabular}

a Deaths per 100000 person-years, standardized to the age distribution of person-time (ages $30-84$ years) observed in the entire cohort.

- Fitted difference between cohort mortality rate and the combined Bucks County, Pennsylvania, and Burlington County, New Jersey, white male mortality rate for the same age and calendar period.

c Fitted ratio of cohort mortality rate and the combined Bucks County and Burlington County white male mortality rate for the same age and calendar period.

posure; the second row displays the person-time that followed the initial exposure, but which was not characterized by the amount of exposure that defined the threshold for that table (listed at the top of the table); the third row gives results for the person-time that was accumulated up to five years following achievement of the threshold level; and the fourth and fifth rows show the corresponding results for the interval 5-19 
Table 5. Accumulated dose of 15 units; mortality from cancer of the colon in the early Bristol cohort among those employed $>10$ months. (95\% Cl=95\% confidence interval)

\begin{tabular}{|c|c|c|c|c|c|c|c|c|}
\hline & Deaths & $\begin{array}{l}\text { Person- } \\
\text { years }\end{array}$ & $\begin{array}{l}\text { Expected } \\
\text { deaths }\end{array}$ & Rate $^{a}$ & $\begin{array}{l}\text { Fitted rate } \\
\text { difference }^{b}\end{array}$ & $95 \% \mathrm{Cl}$ & $\begin{array}{l}\text { Fitted rate } \\
\text { ratio }\end{array}$ & $95 \% \mathrm{Cl}$ \\
\hline Not exposed & 11 & 23487 & 11.48 & 40 & -27 & $-35--18$ & 0.96 & $0.53-1.73$ \\
\hline $\begin{array}{l}\text { Exposed but dose } \\
\text { not achieved }\end{array}$ & 26 & 51552 & 19.81 & 62 & +9 & $-2-+20$ & 1.31 & $0.89-1.93$ \\
\hline \multicolumn{9}{|l|}{$\begin{array}{l}\text { Years since achieve- } \\
\text { ment of dose }\end{array}$} \\
\hline $\begin{array}{l}<5 \\
5-19 \\
\geq 20\end{array}$ & $\begin{array}{r}-1 \\
11\end{array}$ & $\begin{array}{l}1812 \\
5040 \\
5331\end{array}$ & $\begin{array}{l}0.11 \\
0.88 \\
4.58\end{array}$ & $\begin{array}{r}0 \\
11 \\
89\end{array}$ & $\begin{array}{r}-47 \\
+9 \\
+84\end{array}$ & $\begin{array}{l}-81--12 \\
-28-+45 \\
-20-+188\end{array}$ & $\begin{array}{l}0.00 \\
1.13 \\
2.40\end{array}$ & $\begin{array}{r}0-33.6 \\
0.16-8.05 \\
1.33-4.34\end{array}$ \\
\hline
\end{tabular}

a Deaths per 100000 person-years, standardized to the age distribution of person-time (ages $30-84$ years) observed in the entire cohort.

b Fitted difference between cohort mortality rate and the combined Bucks County, Pennsylvania, and Burlington County, New Jersey, white male mortality rate for the same age and calendar period.

c Fitted ratio of cohort mortality rate and the combined Bucks County and Burlington County white male mortality rate for the same age and calendar period.

Table 6. Mortality from cancer of the colon in the early Bristol cohort; mutually exclusive doses of ethyl acrylate/methyl methacrylate at 20 years since first achieving dose among those employed $>10$ months. $(95 \% \mathrm{Cl}=95 \%$ confidence interval)

\begin{tabular}{|c|c|c|c|c|c|c|c|c|}
\hline Achieved dose & $\begin{array}{l}\text { Observed } \\
\text { deaths }\end{array}$ & $\begin{array}{l}\text { Person- } \\
\text { years }\end{array}$ & $\begin{array}{l}\text { Expected } \\
\text { deaths }\end{array}$ & $\begin{array}{l}\text { Standard- } \\
\text { ized rate }\end{array}$ & $\begin{array}{l}\text { Fitted rate } \\
\text { difference }\end{array}$ & $95 \% \mathrm{Cl}$ & $\begin{array}{c}\text { Fitted rate } \\
\text { ratioc }\end{array}$ & $95 \% \mathrm{Cl}$ \\
\hline $\begin{array}{l}\text { None (not exposed) } \\
0-4 \text { units } \\
5-9 \text { units } \\
10-14 \text { units } \\
\geq 15 \text { units }\end{array}$ & $\begin{array}{r}12 \\
13 \\
6 \\
1 \\
11\end{array}$ & $\begin{array}{r}11639 \\
15549 \\
6429 \\
2939 \\
5331\end{array}$ & $\begin{array}{l}9.66 \\
9.39 \\
5.17 \\
2.24 \\
4.58\end{array}$ & $\begin{array}{l}62 \\
65 \\
61 \\
19 \\
89\end{array}$ & $\begin{array}{l}+12 \\
+30 \\
+21 \\
-82 \\
+80\end{array}$ & $\begin{array}{r}-28-+53 \\
-10-+69 \\
-42-+84 \\
-116-+47 \\
-18-+177\end{array}$ & $\begin{array}{l}1.24 \\
1.39 \\
1.16 \\
0.45 \\
2.40\end{array}$ & $\begin{array}{l}0.71-2.19 \\
0.80-2.38 \\
0.52-2.58 \\
0.06-3.16 \\
1.33-4.34\end{array}$ \\
\hline
\end{tabular}

a Deaths per 100000 person-years, standardized to the age distribution of person-time (ages $30-84$ years) observed in the entire cohort.

b Fitted difference between cohort mortality rate and the combined Bucks County, Pennsylvania, and Burlington County, New Jersey, white male mortality rate for the same age and calendar period.

c Fitted ratio of cohort mortality rate and the combined Bucks County and Burlington County white male mortality rate for the same age and calendar period.

years following achievement and $\geq 20$ years following achievement of the threshold dose, respectively. The counts in the first column are the numbers of deaths observed in the different exposure/time categories; the second column gives the accumulated person-time; the third column tabulates the numbers of deaths that would have been expected during the person-time of observation in each exposure/time category, had the local mortality rates recorded for the general population in each observed age and calendaryear category applied exactly to the population observed. The fourth column is the age-standardized mortality rate in the 30- to 84-year-old segment of the worker population. The fifth column presents the fitted estimate of the difference between the mortality rates of each exposure group and the mortality rates in the local population. Accompanying each estimate are the corresponding $95 \%$ confidence intervals. The seventh column presents the fitted rate ratio estimate, which compares the workers' mortality experience in each exposure group again to that of the local population, with the use of a maximum likelihood estimate of the common ratio of one to the other.

Table 2, in which any exposure to EA/MMA is the criterion defining the threshold, shows elevations in mortality in all categories of exposed person-time.
Overall colon cancer mortality in person-time characterized by no prior exposure was no higher than the local rate. The greatest rate difference was seen for $\geq 20$ years after entry into an exposed job. The greatest rate ratio occurred at less than five years. Both the difference and the ratio measures were consistent with a variety of patterns of temporal change because of the uncertainty associated with the point estimates of effect in each time interval. Note that in table 2 persontime cannot logically accrue in the second row when the exposure criterion is " $>0$."

In table 3, the threshold criterion is reset to "at least five units." A portion of the excess colon cancer mortality occurred for those who did not achieve even five units of exposure; for the rest, there was a tendency for the excess to appear at later intervals.

The interpretation of tables 4 and 5 , which posit progressively higher threshold doses, does not differ qualitatively from that of table 3 . The relative and absolute increases at 20 years since achievement of threshold become more pronounced as the threshold level is set at higher and higher values. The apparent excess among those not achieving the threshold is reduced in these latter tables, indicating that the excess in the "exposed but dose not achieved" row of table 3 has been diluted (rather than strengthened) with the addi- 
tion of persons not achieving the higher levels of cumulative exposure.

Mutually exclusive dose categories at 20 years. From tables $2-5$, it appears that the excess mortality rates among the exposed persons were largely confined to the period 20 years or more since the achievement of some relevant level of exposure. From these analyses, it was difficult to identify whether the apparent progressive increase in the relative excess mortality resulted from a smooth "dose-response" effect or from a progressive unmasking of a small volume of person-time with uniquely elevated mortality. Table 6 presents the necessary data. The person-time and the events reported in table 6 all accumulated more than 20 years after first hire. The rows of table 6 correspond to a classification of the time and the deaths according to the accumulated amount of exposure 20 years before. The greatest relative increase in mortality was observed in the highest dose category, that being $\geq 15$ units of exposure accumulated 20 years prior to observation. There was no evidence for a gradual increase in risk associated with increasing exposure at lower doses.

Maximum exposure intensity. The elevation of the mortality rates for colon cancer in the lowest exposure category (table 3, second row) and the general tendency of the workers with the highest cumulative exposure to have had high intensity scores led us to examine whether the apparent dose effect of table 6 might not derive from an intensity effect, that is, if many workers had short terms of employment in the high-intensity jobs and if even short-term exposure conferred risk,

Table 7. Colon cancer observed/expected $(\mathrm{O} / \mathrm{E})$ for the maximum achieved intensity of exposure to ethyl acrylate (EA) and methyl methacrylate (MMA) - early Bristol cohort members employed for $>10$ months.

\begin{tabular}{|c|c|c|c|c|}
\hline $\begin{array}{l}\text { EA/MMA } \\
\text { intensity } \\
\text { level }\end{array}$ & Observed & $\begin{array}{c}\text { Person- } \\
\text { years }\end{array}$ & Expected $^{a}$ & $\mathrm{O} / \mathrm{E}$ \\
\hline \multicolumn{5}{|c|}{$<20$ years since first job } \\
\hline $\begin{array}{l}0 \\
1 \\
2 \\
3 \\
4 \\
5\end{array}$ & $\begin{array}{r}1 \\
4 \\
1 \\
2 \\
- \\
-\end{array}$ & $\begin{array}{r}10816.9 \\
9694.0 \\
5027.5 \\
3418.4 \\
1498.6 \\
11109.8\end{array}$ & $\begin{array}{l}1.87 \\
1.44 \\
0.77 \\
0.40 \\
0.18 \\
1.12\end{array}$ & $\begin{array}{l}0.54 \\
2.78 \\
1.30 \\
5.00 \\
0.00 \\
0.00\end{array}$ \\
\hline \multicolumn{5}{|c|}{$\geq 20$ years since first job } \\
\hline $\begin{array}{l}0 \\
1 \\
2 \\
3 \\
4 \\
5\end{array}$ & $\begin{array}{r}10 \\
8 \\
7 \\
1 \\
1 \\
14\end{array}$ & $\begin{array}{r}9990.1 \\
8465.6 \\
3917.2 \\
2956.3 \\
1347.3 \\
10289.6\end{array}$ & $\begin{array}{l}8.85 \\
6.20 \\
2.73 \\
2.16 \\
1.09 \\
7.53\end{array}$ & $\begin{array}{l}1.13 \\
1.29 \\
2.56 \\
0.46 \\
0.92 \\
1.86\end{array}$ \\
\hline
\end{tabular}

then high-risk persons with low cumulative exposures (less than five units) could well have affected the mortality results in the second row of table 3. In table 7, the person-time of all the workers after their start of the highest intensity job experienced by each worker is presented in categories further defined by achievement of 20 years of experience since the start of the job. In each category, table 7 displays the number of deaths from colon cancer, the person-years of experience accumulated, the expected number of deaths, based on the combined Bucks and Burlington county rates, and the ratio of observed-to-expected deaths. There was no pattern suggestive of a regular increase in relative mortality with increasing maximal intensity of exposure to EA/MMA. To the contrary, the highest observed-to-expected value in the $\geq 20$-year group was found for those with a maximal exposure level of two, a group characterized by a variety of nonEA/MMA exposures.

Essentially all men who achieved a cumulative exposure score of six or more units did so by working at jobs rated 5 for three or more years. Subtracting the 11 deaths and the 4.58 expected deaths given in table 6 from the corresponding values in the lower half of table 7 (14 and 7.53, respectively) leads to a residual of 3 observed and 2.95 expected deaths among the men who were exposed to level 5 jobs for less than three years.

Date of hire. We further separated the experience of the workers at the Bristol plant according to the year in which they were hired to investigate the possibility that the elevated mortality associated with high cumulative exposure may have been an artifact of hiring practices during the Second World War, a period in which the regional origins and health characteristics of newly hired men might be expected to have been different from those of the population providing workers to the plant in peacetime. Since most of the high accumulated dose exposure occurred among the men hired in 1940-1942, the association between EA/ MMA and mortality might have been confounded by such effects. We therefore separated person-time, deaths, and expected deaths according to date of hire (before 1940, 1940-1942, after 1942), time interval since hire $(<20$ years, $\geq 20)$, and accumulation of 15 or more units of exposure. Of the men hired before 1940 , we considered only those whose employment extended after 1940. After 1942 there were essentially no new employees who accumulated 15 units of exposure. In the comparison of the men hired before 1940 (SMR $=3.1$, on the basis of five observed deaths) to those hired later ( $\mathrm{SMR}=2.1$, on the basis of six observed deaths) there was no evidence that the elevated mortality that characterized the men 20 years or more after the accumulation of 15 units of exposure was restricted to those hired during the war years. 
Characteristics of decedents. Review of the job histories of the 11 decedents in the highest category of achieved exposure to EA/MMA did not reveal common job titles, common exposures to possible or probable carcinogens, or other common characteristics, other than high exposure to EA/MMA. None worked in fabrication or finishing operations.

\section{Early Bristol rectal cancer}

Table 8 presents the occurrence of rectal cancer according to the mutually exclusive accumulated dose categories that were employed in table 6 . There was a paucity of data for the observed person-time, largely as a result of the much lower rate for rectal than for colon cancer. There were elevations in the rate ratio measures for the $0-4,10-14$, and $\geq 15$ unit dose categories, and there were deficits in the unexposed and in the 5-9 unit dose category. Among the exposed persons overall there were 10 deaths observed and 5.23 expected, for an observed-to-expected ratio of 1.9 (exact $95 \%$ CI $0.92-3.4$ ).

\section{Later Bristol}

Colon cancer. Table 9 presents the relation between accumulated EA/MMA dose at 20 years and the risk of colon cancer death. There was very little persontime in the highest dose categories. Even when the noncomparability of the exposure scales is allowed for, it is probable that the most highly exposed job histories of the early Bristol cohort would be categorized in one of the top two exposure levels of the later Bristol scoring system. The absence of meaningful amounts of person-time in the high exposure categories means that analysis of these data provided no relevant information to test the hypothesis of increased risk at long intervals after very high exposure that was raised by the analysis of the early Bristol data. There was no indication of an elevated risk at lower levels of exposure, for which the accumulated experience was substantial. The small number of person-years of observation in the higher exposure categories, represented by the last two rows of table 9, emphasizes a limitation in the available data, namely, the exposures to EA/MMA that characterized the early Bristol cohort were so different from those that came later that subsequent worker experience, while reassuring in itself, had very little relevance to the understanding of what may have occurred in the early years to workers with high cumulative exposures.

Rectal cancer. As indicated in table 9, there were no deaths from rectal cancer more than 20 years after hire. (There were no deaths at all from rectal cancer in the later Bristol cohort.)

\section{Knoxville}

Colon cancer. At 20 years after exposure, the relation between colon cancer mortality and dose showed

Table 8. Mortality from cancer of the rectum in the early Bristol cohort; mutually exclusive doses of ethyl acrylate/methyl methacrylate at 20 years since first achieving dose among those employed $>10$ months. $(95 \% \mathrm{Cl}=95 \%$ confidence interval)

\begin{tabular}{|c|c|c|c|c|c|c|c|c|}
\hline Achieved dose & $\begin{array}{l}\text { Observed } \\
\text { deaths }\end{array}$ & $\begin{array}{l}\text { Person- } \\
\text { years }\end{array}$ & $\begin{array}{c}\text { Expected } \\
\text { deaths }\end{array}$ & $\begin{array}{l}\text { Standard- } \\
\text { ized rate }\end{array}$ & $\begin{array}{l}\text { Fitted rate } \\
\text { difference }^{b}\end{array}$ & $95 \% \mathrm{Cl}$ & $\begin{array}{l}\text { Fitted rate } \\
\text { ratioc }^{c}\end{array}$ & $95 \% \mathrm{Cl}$ \\
\hline $\begin{array}{l}\text { None (not exposed) } \\
0-4 \text { units } \\
5-9 \text { units } \\
10-14 \text { units } \\
\geq 15 \text { units }\end{array}$ & $\begin{array}{r}2 \\
6 \\
-1 \\
3\end{array}$ & $\begin{array}{r}11639 \\
15549 \\
6429 \\
2939 \\
5331\end{array}$ & $\begin{array}{l}2.78 \\
2.39 \\
1.24 \\
0.54 \\
1.06\end{array}$ & $\begin{array}{r}5 \\
26 \\
0 \\
22 \\
29\end{array}$ & $\begin{array}{l}-38 \\
+12 \\
-38 \\
+24 \\
+33\end{array}$ & $\begin{array}{l}-50--26 \\
-10-+34 \\
-53--22 \\
-49-+97 \\
-27-+93\end{array}$ & $\begin{array}{l}0.72 \\
2.52 \\
0.00 \\
1.85 \\
2.83\end{array}$ & $\begin{array}{r}0.18-2.88 \\
1.13-5.60 \\
0-2.98 \\
0.26-13.1 \\
0.91-8.76 .\end{array}$ \\
\hline
\end{tabular}

a Deaths per 100000 person-years, standardized to the age distribution of person-time (ages $30-84$ years) observed in the entire cohort.

b Fitted difference between cohort mortality rate and the combined Bucks County, Pennsylvania, and Burlington County, New Jersey, white male mortality rate for the same age and calendar period.

c Fitted ratio of cohort mortality rate and the combined Bucks County and Burlington County white male mortality rate for the same age and calendar period.

Table 9. Mortality from cancers of the colon and rectum in the later Bristol cohort; mutually exclusive doses of ethyl acry. late/methyl methacrylate at 20 years since first achieving dose. $(95 \% \mathrm{Cl}=95 \%$ confidence interval)

\begin{tabular}{|c|c|c|c|c|c|c|c|c|c|c|c|}
\hline \multirow{2}{*}{$\begin{array}{l}\text { Achieved } \\
\text { dose }\end{array}$} & \multicolumn{2}{|c|}{$\begin{array}{c}\text { Observed } \\
\text { deaths }\end{array}$} & \multirow{2}{*}{$\begin{array}{l}\text { Person- } \\
\text { years }\end{array}$} & \multicolumn{2}{|c|}{$\begin{array}{c}\text { Expected } \\
\text { deaths }\end{array}$} & \multirow{2}{*}{\multicolumn{2}{|c|}{$\begin{array}{c}\begin{array}{c}\text { Standardized } \\
\text { rate }^{\mathrm{a}}\end{array} \\
\text { Colon Rectum }\end{array}$}} & \multicolumn{2}{|c|}{$\begin{array}{c}\text { Fitted rate } \\
\text { ratio }\end{array}$} & \multicolumn{2}{|c|}{$95 \% \mathrm{Cl}$} \\
\hline & Colon & Rectum & & Colon & Rectum & & & Colon & Rectum & Colon & Rectum \\
\hline $\begin{array}{l}\text { None (not exposed) } \\
0-4 \text { units } \\
5-9 \text { units } \\
10-14 \text { units } \\
\geq 15 \text { units }\end{array}$ & $\begin{array}{r}8 \\
6 \\
1 \\
- \\
-\end{array}$ & $\begin{array}{l}- \\
- \\
- \\
-\end{array}$ & $\begin{array}{r}22061 \\
16712 \\
1643 \\
732 \\
334\end{array}$ & $\begin{array}{l}8.19 \\
5.55 \\
0.80 \\
0.46 \\
0.24\end{array}$ & $\begin{array}{l}1.58 \\
1.11 \\
0.13 \\
0.07 \\
0.03\end{array}$ & $\begin{array}{r}14 \\
20 \\
27 \\
0 \\
0\end{array}$ & $\begin{array}{l}0 \\
0 \\
0 \\
0 \\
0\end{array}$ & $\begin{array}{l}0.98 \\
1.08 \\
1.26 \\
0.00 \\
0.00\end{array}$ & $\begin{array}{l}0.00 \\
0.00 \\
0.00 \\
0.00 \\
0.00\end{array}$ & $\begin{array}{r}0.49-1.95 \\
0.49-2.41 \\
0.18-8.92 \\
0-8.04 \\
0-15.2\end{array}$ & $\begin{array}{l}0-2.34 \\
0-3.33 \\
0-28.5 \\
0-56.7 \\
0-106\end{array}$ \\
\hline
\end{tabular}

a Deaths per 100000 person-years, standardized to the age distribution of person-time (ages $30-84$ years) observed in the entire cohort. b Fitted ratio of cohort mortality rate and the combined Bucks County and Burlington County white male mortality rate for the same age and calen- 
Table 10. Mortality from cancers of the colon and rectum in the Knoxville cohort; mutually exclusive doses of ethyl acrylate/methyl methacrylate at 20 years since first achieving dose. $(95 \% \mathrm{Cl}=95 \%$ confidence interval)

\begin{tabular}{|c|c|c|c|c|c|c|c|c|c|c|c|}
\hline \multirow{2}{*}{$\begin{array}{l}\text { Achieved } \\
\text { dose }\end{array}$} & \multicolumn{2}{|c|}{$\begin{array}{l}\text { Observed } \\
\text { deaths }\end{array}$} & \multirow{2}{*}{$\begin{array}{c}\text { Person- } \\
\text { years }\end{array}$} & \multicolumn{2}{|c|}{$\begin{array}{l}\text { Expected } \\
\text { deaths }\end{array}$} & \multirow{2}{*}{\multicolumn{2}{|c|}{$\begin{array}{c}\begin{array}{c}\text { Standardized } \\
\text { rate }^{\mathrm{a}}\end{array} \\
\text { Colon Rectum }\end{array}$}} & \multicolumn{2}{|c|}{$\begin{array}{c}\text { Fitted rate } \\
\text { ratiob }\end{array}$} & \multicolumn{2}{|c|}{$95 \% \mathrm{Cl}$} \\
\hline & Colon & Rectum & & Colon & Rectum & & & Colon & Rectum & Colon & Rectum \\
\hline $\begin{array}{l}\text { None (not exposed) } \\
0-4 \text { units } \\
5-9 \text { units } \\
10-14 \text { units } \\
\geq 15 \text { units }\end{array}$ & $\begin{array}{r}-17 \\
1 \\
\frac{1}{1}\end{array}$ & $\begin{array}{l}- \\
- \\
- \\
-\end{array}$ & $\begin{array}{r}2316 \\
24162 \\
2659 \\
1374 \\
2293\end{array}$ & $\begin{array}{l}0.80 \\
9.19 \\
1.01 \\
0.67 \\
1.60\end{array}$ & $\begin{array}{l}0.19 \\
2.30 \\
0.25 \\
0.15 \\
0.35\end{array}$ & $\begin{array}{r}-27 \\
16 \\
0 \\
13\end{array}$ & $\begin{array}{l}- \\
2 \\
0 \\
0 \\
0\end{array}$ & $\begin{array}{l}0.00 \\
1.85 \\
0.00 \\
0.00 \\
0.63\end{array}$ & $\begin{array}{l}0.00 \\
0.44 \\
0.00 \\
0.00 \\
0.00\end{array}$ & $\begin{array}{r}0-4.63 \\
1.15-2.98 \\
0-3.66 \\
0-5.52 \\
0.09-4.44\end{array}$ & $\begin{array}{r}0-19.5 \\
0.06-3.09 \\
0-14.8 \\
0-24.7 \\
0-10.6\end{array}$ \\
\hline
\end{tabular}

a Deaths per 100000 person-years, standardized to the age distribution of person-time (ages $30-84$ years) observed in the entire cohort.

b Fitted ratio of cohort mortality rate and the combined Bucks County and Burlington County white male mortality rate for the same age and calen dar period.

deficits at higher exposure levels and excess at the lowest level (table 10). There were no colon cancer deaths among the unexposed. Only a very small number of men at Knoxville had no exposure at all; the corresponding accumulated person-time was so small that it was not possible to evaluate the "base-line" mortality for this group.

Rectal cancer. There was a single rectal cancer death, in the lowest exposure group (table 10).

\section{Discussion}

A previously noted excess of deaths from colon cancer among men who have worked with EA and MMA appears to be largely restricted to those who worked extensively in the early 1940s in jobs that entailed presumed high exposure to the vapor phase of EA and MMA monomer and to volatile by-products of the EA/MMA polymerization process. The excess mortality did not appear until some two decades had elapsed after the men had accumulated the equivalent of three years of employment in the most intensely exposed jobs. The presence of other, possibly harmful, chemicals in the work environment of the men in the high-exposure jobs has not been ruled out, but there was no available evidence that pointed to substances associated with the greatest EA/MMA exposures.

The observation time of the Knoxville cohort, represented in the last two rows of table 10 , is drawn entirely from those workers whose experience parallels in time the experience of the post-1942 hires of the early Bristol cohort. Neither is characterized by an elevated risk of colon cancer.

Because of later reductions in exposure, very few men hired after 1942 in Bristol had an opportunity to accumulate 15 units of exposure to EA/MMA. To the extent that the processes were the same in Knoxville and Bristol at the same time, as they appear to have been, there would have been a similarly reduced exposure opportunity in Knoxville. There has been no excess of colorectal cancer mortality among the men who held high-exposure jobs for short periods of time in the early Bristol cohort. Men who were hired after
1942 at Bristol and who worked in jobs rated as high intensity showed no excess mortality from colorectal cancer. Neither men in Knoxville, who were hired beginning in 1943, nor men in the later Bristol cohort, who were hired in 1946 and later, showed an excess mortality from cancers of the colon or rectum.

Because of the limited cumulative exposure opportunity after 1942 in Bristol and Knoxville, the available data do not permit us to address possible effects of the change in the EA/MMA mixture that occurred early in 1943.

Rectal cancer mortality in the early Bristol cohort was elevated in the same categories, marked by high exposure and long intervals since exposure, that showed excess rates of colon cancer death. Because of the much lower rates of rectal than of colon cancer mortality, there was much more variability in the results; by themselves, therefore, the rectal cancer findings in the early Bristol cohort would be considered to constitute only weak evidence in favor of increased risk. There were notable deficits of rectal cancer mortality in both the later Bristol and the Knoxville cohorts.

Collins and his colleagues (3) found one death from cancer of the large intestine as opposed to $2.6 \mathrm{ex}$ pected among 1561 men exposed to MMA fumes at concentrations on the order of $1 \mathrm{ppm}$ while employed at the American Cyanamid Company during the period 1951-1973. No rectal cancer deaths were observed. None of the reported exposure involved EA or volatile by-products of EA/MMA polymerization. It is not possible to gauge the relative intensity of MMA exposure of those workers in comparison with that of the men at the Bristol or Knoxville facilities. The allcause mortality in the American Cyanamid study was only $67 \%$ of the expected; therefore the possibility of incomplete ascertainment of deaths is raised. The study report did not segregate the experience of workers with high levels of exposure or with a long time since exposure. These gaps notwithstanding, since neither the Knoxville workers nor the Bristol workers hired after 1942 exhibited any elevation in cancers of the colon or rectum, it is entirely possible that the American Cyanamid results, stemming from more recent exposures, reflect an absence of elevation of risk 
that characterizes contemporary acrylate workers at both firms.

There was evidence of smaller increases in colorectal cancer mortality for workers who had low exposures to EA and MMA, but who may have been further characterized by transdermal and respiratory exposure to the solvents ethylene dichloride, methylene chloride, acetone, and MMA monomer. It should be noted that the extensive efforts that were devoted to assessing EA/MMA exposure were not extended to other chemicals. As a result, available data on exposure to agents other than EA/MMA were incomplete and anecdotal.

From review of the job histories of persons who died of colon cancer in the highest EA/MMA exposure categories, and within the limits of available information on the workplace distribution of exposures other than EA/MMA, it does not appear that confounding by other chemicals explains the association of mortality with the highest achieved doses of EA/MMA.

The finding of an excess mortality for colon and rectal cancer in a circumscribed part of the study population is not readily ascribable to known confounding or to other forms of bias. The result appears to be restricted to a single locale, and a stage now decades past in the historical development of the process of acrylic sheet manufacture. The origin of the present finding might be ascribed to chance by many reasonable persons, except that the class of person-time within which the excess mortality from cancers of the colon and rectum appeared is, by best accounts, that one in which exposure to EA/MMA was the greatest. A causal role for protracted, extremely high exposures to EA, MMA, or the volatile by-products of the EA/MMA polymerization process in the genesis of colon and rectum cancer is a tenable explanation of the available epidemiologic data. It accounts for the excess mortality that was observed in specific times at a single place, and it accounts for the absence of similar excesses elsewhere in the data. Other tenable explanations could invoke any agent that was so intimately associated with the EA/MMA polymerization process carried out in the Bristol plant before 1945 as to be found there and not elsewhere.

The tenability of a causal hypothesis concerning the role of EA is not supported by any known biological mechanism. EA has been given a carcinogenicity rating of 2B by the International Agency for Research on Cancer (4) on the basis of the appearance of squamous cell papillomas and carcinomas of the forestomachs of rats and mice given $100-200 \mathrm{mg}$ of EA/ $\mathrm{kg}$ of body weight by gavage five times a week for two years (5). In the same studies, there were no detectable blood levels of EA in the systemic circulation, a finding sug- gesting the unlikelihood of effects of EA beyond the immediate site of administration. Inhalation studies (6) and lifetime skin application studies (7) have been negative. As might be anticipated from the rapid metabolism of EA in vivo (6), there is no experimental evidence of carcinogenesis at a distant site.

The fundamental exposure measure employed in this work was a cumulative score. While this was the only technique for summarizing exposure that was reasonably available to us, we should note several common limitations to the method. First, any incremental risk associated with a unit of exposure ought to be the same at all levels of the exposure scale; otherwise slow accumulation of a total exposure score will not entail the same degree of risk as will rapid accumulation to the same score over a short period. Second, the effect of past exposure on risk ought not change greatly over the period of exposure accumulation; otherwise the slowly accumulated dose measure will be distorted by the effect of time over the interval separating the first from the last accumulated instances of exposure. The relative uniformity of exposure, with almost complete absence of elevated exposure in the later Bristol cohort, makes these arguments academic for that group. In the earlier Bristol and Knoxville cohorts, the possible problems are mitigated by the relative brevity of the interval over which high exposures were accumulated (three to five years), as seen in comparison with the length of follow-up, which extended for another 40 years.

\section{References}

1. Royal Statistical Society. GLIM system release 3.77. Oxford: Numerical Algorithms Group Ltd, 1986.

2. Walker AM. Small sample properties of some estimators of a common hazard ratio. Appl Stat 1985;34:42-8.

3. Collins JJ, Page LC, Carporossi JC, Utidjian HM, Saipher JN. Mortality patterns among men exposed to methyl methacrylate. J Occup Med 1989;31:41-6.

4. IARC Working Group on the Evaluation of Carcinogenic Risk of Chemicals to Humans. Some chemicals used in plastics and elastomers. International Agency for Research on Cancer, Lyon, 1986. (Volume 39.)

5. National Toxicology Program. NTP technical report on the carcinogenesis studies of ethyl acrylate (CAS no $140-88-5$ ) in $\mathrm{F} 344 / \mathrm{N}$ rats and $\mathrm{B} 6^{\circ} \mathrm{C} 3 \mathrm{~F}$, Mice (gavage studies). Research Triangle Park, NC: National Toxicology Program, 1983. (Technical report series; no 259.)

6. Miller RR, Young JT, Kociba RJ, et al. Chronic toxicity and oncogenicity bioassay of inhaled ethyl acrylate in Fischer 344 rates and $\mathrm{B} 6{ }^{\circ} \mathrm{C} 3 \mathrm{~F} 1$ mice. Drug Chem Toxicol $1985 ; 8: 1-42$.

7. DePass LR, Fowler EH, Meckley DR, Weil CS. Dermal oncogenicity bioassays of acrylic acid, ethyl acrylate, and butyl acrylate. J Toxicol Environ Health 1984;14:115-20. 


\section{Appendix}

\section{The general mortality experience of the Rohm \& Haas cohorts}

We calculated standard mortality ratios (SMR) for 62 causes of death for each of the three cohorts. The observed deaths were coded initially according to the revision of the International Classification of Diseases in effect at the time of death. The resulting codes were then mapped onto the codes for the eighth revision of the Classification (1). We derived the counts of expected deaths by applying the mortality rates for white

Table A1. Observed $(O)$ and expected $(E)$ numbers of deaths in the early Bristol, later Bristol, and Knoxville cohorts. (SMR = standardized mortality ratio)

\begin{tabular}{|c|c|c|c|c|c|c|c|c|c|}
\hline \multirow{2}{*}{ Cause of death } & \multicolumn{3}{|c|}{ Early Bristol } & \multicolumn{3}{|c|}{ Later Bristol } & \multicolumn{3}{|c|}{ Knoxville } \\
\hline & 0 & $E$ & SMR & 0 & $E$ & SMR & 0 & $E$ & SMR \\
\hline All causes of death & 1992 & 2202.94 & 0.90 & 981 & 1011.18 & 0.97 & 1133 & 1072.51 & 1.06 \\
\hline Tuberculosis & 12 & 8.37 & 1.43 & 4 & 2.82 & 1.42 & 9 & 3.77 & 2.39 \\
\hline All malignant neoplasms & $43 \overline{3}$ & 448.91 & 0.96 & 230 & 225.78 & 1.02 & 261 & 231.25 & 1.13 \\
\hline Cancer of buccal cavity \& pharynx & 8 & 13.42 & 0.60 & 2 & 6.95 & 0.29 & 11 & 7.01 & 1.57 \\
\hline Cancer of digestive organs \& peritoneum & 139 & 126.52 & 1.11 & 49 & 53.95 & 0.94 & 49 & 61.06 & 0.80 \\
\hline Cancer of esophagus & 12 & 10.48 & 1.14 & 4 & 5.44 & 0.74 & 4 & 5.46 & 0.73 \\
\hline Cancer of stomach & 17 & 24.59 & 0.69 & 14 & 8.52 & 1.64 & 7 & 10.81 & 0.65 \\
\hline Cancer of large intestine & 62 & 42.18 & 1.47 & 17 & 18.73 & 0.91 & 20 & 20.74 & 0.96 \\
\hline Cancer of rectum & 17 & 13.87 & 1.23 & - & 5.06 & 0.00 & 1 & 6.34 & 0.16 \\
\hline Cancer of biliary passages \& liver & 6 & 7.37 & 0.81 & 1 & 3.78 & 0.26 & 7 & 3.85 & 1.82 \\
\hline Cancer of pancreas & 22 & 24.15 & 0.91 & 11 & 11.39 & 0.96 & 10 & 12.25 & 0.82 \\
\hline Cancer of all other digestive organs & 3 & 3.88 & 0.77 & 2 & 1.03 & 1.94 & - & 1.61 & 0.00 \\
\hline Cancer of respiratory system & 148 & 149.80 & 0.99 & 90 & 85.64 & 1.05 & 119 & 82.64 & 1.44 \\
\hline Cancer of larynx & 3 & 6.46 & 0.46 & 7 & 3.17 & 2.21 & 3 & 3.34 & 0.90 \\
\hline Cancer of bronchus, trachea, lung & 141 & 141.41 & 1.00 & 82 & 81.41 & 1.01 & 115 & 78.27 & 1.47 \\
\hline Cancer of all other respiratory & 4 & 1.93 & 2.07 & 1 & 1.06 & 0.94 & 1 & 1.03 & 0.97 \\
\hline Cancer of breast & - & 0.64 & 0.00 & 1 & 0.30 & 3.31 & 1 & 0.32 & 3.13 \\
\hline Cancer of prostate & 32 & 37.90 & 0.84 & 10 & 9.52 & 1.05 & 12 & 15.48 & 0.78 \\
\hline Cancer of testes \& other male genital organs & 3 & 1.88 & 1.59 & 3 & 1.85 & 1.62 & 3 & 1.21 & 2.47 \\
\hline Cancer of kidney & 6 & 10.62 & 0.56 & 7 & 5.98 & 1.17 & 7 & 5.73 & 1.22 \\
\hline Cancer of bladder \& other urinary organs & 11 & 14.86 & 0.74 & 4 & 4.67 & 0.86 & 8 & 6.54 & 1.22 \\
\hline Malignant melanoma of skin & 6 & 4.74 & 1.27 & 3 & 4.64 & 0.65 & 2 & 3.16 & 0.63 \\
\hline Cancer of eye & 1 & 0.39 & 2.54 & - & 0.17 & 0.00 & 1 & 0.19 & 5.22 \\
\hline Cancer of central nervous system & 11 & 11.28 & 0.98 & 11 & 8.69 & 1.27 & 10 & 6.94 & 1.44 \\
\hline Cancer of thyroid gland \& other endocrine giands & 2 & 1.52 & 1.31 & 1 & 0.84 & 1.19 & - & 0.81 & 0.00 \\
\hline Cancer of bone & 2 & 1.95 & 1.03 & 3 & 0.96 & 3.11 & 1 & 0.96 & 1.04 \\
\hline Cancer of all lymphatic \& hematopoietic tissue & 25 & 41.74 & 0.60 & 25 & 23.95 & 1.04 & 22 & 22.39 & 0.98 \\
\hline Lymphosarcoma \& reticulosarcoma & 1 & 8. 16 & 0.12 & 2 & 4.35 & 0.46 & 6 & 4.33 & 1.39 \\
\hline Hodgkin's disease & 5 & 4.17 & 1.20 & 3 & 3.27 & 0.92 & 3 & 2.50 & 1.20 \\
\hline Leukemia \& aleukemia & 12 & 17.32 & 0.69 & 10 & 9.16 & 1.09 & 4 & 8.92 & 0.45 \\
\hline Cancer of all other lymphopoietic tissue & 7 & 12.09 & 0.58 & 10 & 7.17 & 1.39 & 9 & 6.64 & 1.36 \\
\hline All other malignant neoplasms & 39 & 31.65 & 1.23 & 21 & 17.67 & 1.19 & 15 & 16.81 & 0.89 \\
\hline Benign neoplasms & 5 & 3.93 & 1.27 & 1 & 2.61 & 0.38 & 2 & 2.28 & 0.88 \\
\hline Diabetes mellitus & 35 & 31.45 & 1.11 & 15 & 13.99 & 1.07 & 12 & 15.29 & 0.78 \\
\hline Cerebrovascular disease & 138 & 157.26 & 0.88 & 41 & 41.98 & 0.98 & 68 & 63.13 & 1.08 \\
\hline All heart disease & 910 & 949.04 & 0.96 & 425 & 373.56 & 1.14 & 416 & 442.19 & 0.94 \\
\hline Rheumatic heart disease & 25 & 19.59 & 1.28 & 8 & 9.64 & 0.83 & 7 & 10.22 & 0.68 \\
\hline Ischemic heart disease & 800 & 868.07 & 0.92 & 375 & 335.71 & 1.12 & 366 & 403.18 & 0.91 \\
\hline Chronic disease of endocardium; & & & & & & & & & \\
\hline myocardial insufficiency & 17 & 18.19 & 0.94 & 4 & 6.96 & 0.58 & 2 & 8.08 & 0.25 \\
\hline Hypertension with heart disease & 16 & 14.84 & 1.08 & 7 & 5.58 & 1.26 & 7 & 6.57 & 1.06 \\
\hline All other heart disease & 52 & 28.35 & 1.83 & 31 & 15.67 & 1.98 & 34 & 14.44 & 2.40 \\
\hline Hypertension without heart disease & 10 & 6.66 & 1.50 & 1 & 1.93 & 0.52 & 4 & 2.70 & 1.48 \\
\hline Nonmalignant respiratory disease & 121 & 155.44 & 0.78 & 46 & 53.29 & 0.86 & 76 & 63.37 & 1.10 \\
\hline Influenza \& pneumonia & 39 & 60.71 & 0.64 & 9 & 18.41 & 0.49 & 25 & 24.73 & 1.01 \\
\hline Bronchitis, emphysema, asthma & 33 & 45.62 & 0.72 & 14 & 13.61 & 1.03 & 21 & 20.31 & 1.03 \\
\hline Bronchitis & 5 & 7.58 & 0.66 & - & 2.19 & 0.00 & 3 & 3.31 & 0.91 \\
\hline Emphysema & 27 & 35.15 & 0.77 & 13 & 10.23 & 1.27 & 17 & 15.65 & 1.09 \\
\hline Asthma & 1 & 3.01 & 0.33 & 1 & 1.15 & 0.87 & 1 & 1.37 & 0.73 \\
\hline Other nonmalignant respiratory disease & 49 & 49.11 & 1.00 & 23 & 21.27 & 1.08 & 30 & 24.33 & 1.23 \\
\hline Ulcer of stomach \& duodenum & 13 & 14.18 & 0.92 & 2 & 4.69 & 0.43 & 6 & 6.28 & 0.96 \\
\hline Cirrhosis of liver & 30 & 45.02 & 0.67 & 26 & 34.04 & 0.7 & 17 & 27.40 & 0.62 \\
\hline Nephritis \& nephrosis & 12 & 11.38 & 1.06 & 2 & 4.82 & 0.42 & 7 & 5.35 & 1.31 \\
\hline All external causes of death & 82 & 155.20 & 0.53 & 86 & 157.50 & 0.55 & 90 & 102.09 & 0.88 \\
\hline Accidents & 62 & 101.09 & 0.61 & 47 & 100.12 & 0.47 & 51 & 65.15 & 0.78 \\
\hline Motor vehicle accidents & 27 & 46.22 & 0.58 & 24 & 53.68 & 0.45 & 13 & 31.90 & 0.41 \\
\hline All other accidents & 35 & 54.97 & 0.64 & 23 & 46.73 & 0.49 & 38 & 33.35 & 1.14 \\
\hline Suicides & 19 & 36.13 & 0.53 & 27 & 35.65 & 0.76 & 19 & 24.00 & 0.79 \\
\hline Homicides \& other external causes & 1 & 17.98 & 0.06 & 12 & 21.73 & 0.55 & 20 & 12.94 & 1.55 \\
\hline All other causes of death & 191 & 216.10 & 0.88 & 102 & 94.17 & 1.08 & 165 & 106.76 & 1.55 \\
\hline Unknown causes & - & $\cdots$ & & - & $\cdots$ & $\cdots$ & - & $\cdots$ & 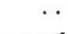 \\
\hline
\end{tabular}

a Expected numbers of deaths derived from white male death rates in the United States. 
males in the United States to the person-time of the cohort in each cross-classified category of age $(<20$ years to $\geq 85$ years in five-year increments) and calendar period (from 1933-1986, 1946-1986, and 19431986 for the early Bristol, later Bristol, and Knoxville cohorts, respectively, in five-year intervals), and then summing over the age/calendar period categories. Mortality data were unavailable prior to 1950 ; therefore 1950 rates were applied to person-time accrued prior to that year. The SMR was calculated as the ratio of observed-to-expected deaths for each cause of death. A valid SMR greater than 1.0 indicated excess mortality, while an SMR less than 1.0 indicated that mortality was below the levels that would be expected if the cohort's mortality rates were identical to those of the United States generally. The OCMAP (occupational cohort mortality analysis program) (2) for personal computers was used to allocate the person-time and observed deaths and to calculate the SMR values. Table Al presents the observed deaths, expected deaths, and SMR values for the early Bristol, later Bristol, and Knoxville cohorts.

\section{References}

1. World Health Organization. Manual of the international classification of diseases; vol 1. 8th revision. Geneva, World Health Organization, 1965.

2. Marsh GM, Preininger M. OCMAP: a user-oriented occupational cohort mortality analysis program. Am Stat $1980 ; 34: 245$.

Received for publication: 2 April 1990 